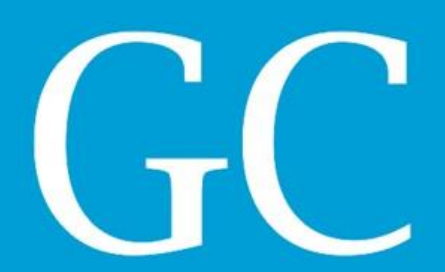

ISSN 2318-8472

Revista Nacional de

Gerenciamento de Cidades

National Joumal of Cities Management

\title{
Ferrovia e infraestrutura de abastecimento de água: o caso de Lençóis Paulista
}

Railroad and water supply infrastructure: the case of Lençóis Paulista

Ferrocarril e infraestructura de abastecimiento de agua: el caso de Lençóis Paulista

Érica Lemos Gulinelli Professora Mestra, USC, Brasil. ericagulinelliarq@gmail.com

Ivone Salgado Professora Doutora, PUC CAMPINAS, Brasil. salgadoivone@uol.com.br 


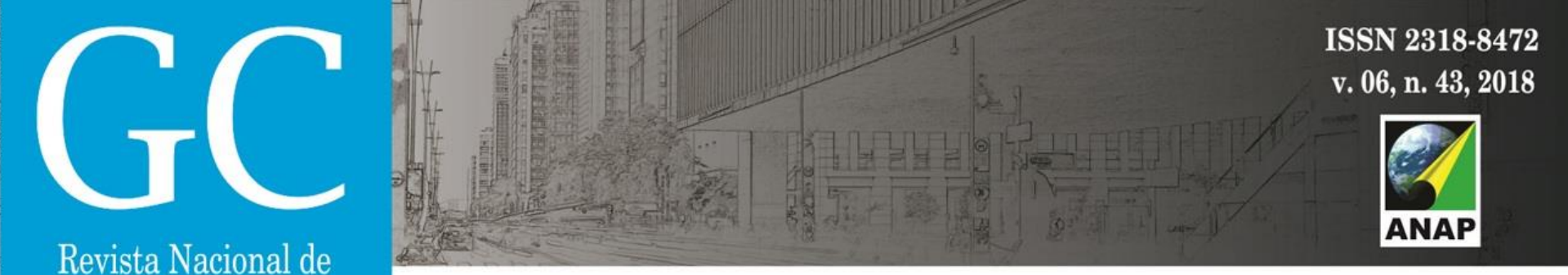

Revista Nacional de Gerenciamento de Cidades

\section{INTRODUÇÃO}

Este artigo é parte de uma pesquisa mais ampla que busca entender o fomento da implantação de infraestrutura urbana, sobretudo no sistema de abastecimento de água, em cidades do oeste paulista, que tiveram a ferrovia como propulsora deste processo. Desta forma, trataremos aqui da cidade de Lençóis Paulista, localizada no oeste do Estado de São Paulo, a $289 \mathrm{Km}$ da capital paulista.

A formação do território urbano e a ferrovia estão diretamente ligados com a questão das águas de abastecimento. A demanda do acesso a água é amplamente discutida no que tange o saneamento urbano e a questão do seu patrimônio. A água pura para se beber, no território de Lençóis foi sempre um problema difícil. A corrente que forneciam a água aos moradores era do Rio Lençóis, que não se recomendavam por serem poluídas pelos animais que dela desfrutavam, além de estarem sujas e cheia de detritos. O líquido era recolhido diretamente dos córregos, sem tratamento algum.

O objetivo do trabalho inclui analisar a formação do território de Lençóis, evolução da cidade, a vinda da ferrovia e o surgimento dos melhoramentos e infraestrutura na urbe, no período de sua formação até a década de 1940. Como também, entender como a chegada dos trilhos propiciou o desenvolvimento do abastecimento de água na cidade, bem como demonstrar a evolução deste sistema no recorte temporal de estudo.

Para a construção do cenário de Lençóis, no recorte temporal proposto, embasou-se os estudos principalmente na pesquisa documental em fontes primárias. Na busca por informações da história urbana da cidade e a questão da ferrovia, foram visitados arquivos da Câmara Municipal, Prefeitura Municipal, bem como o Museu Alexandre Chitto e o Núcleo de Pesquisa Histórica da Universidade Sagrado Coração (NUPHIS-USC). Entre os documentos levantados, foram analisados: atas de câmaras, decretos, fotos antigas, mapas, memórias. Todo este material foi importante para delinearmos as conjunturas históricas e entender todo o processo de instalação da ferrovia e do sistema de abastecimento de água.

Como bibliografia complementar, focados na temática da pesquisa, utilizou-se de outras fontes tais como: livros, artigos, teses, dissertações. Todo este conjunto de informações foi organizado para delinear o artigo, sempre apoiados nos dados do material primário.

\section{LENÇÓIS PAULISTA: HISTORIOGRAFIA SOBRE A FORMAÇÃO DO TERRITÓRIO E SURGIMENTO DA CIDADE}

Os primeiros povoadores teriam vindo no início do século XIX para a região que pertencia ao território de Botucatu. Os pioneiros apareceram de diferentes regiões buscando as terras disponíveis e férteis, fixando-se próximos aos rios e expulsando os índios, habitantes já existentes. Eram lavradores e criadores oriundos de Sorocaba, Mogi-Mirim, Itapetininga, 


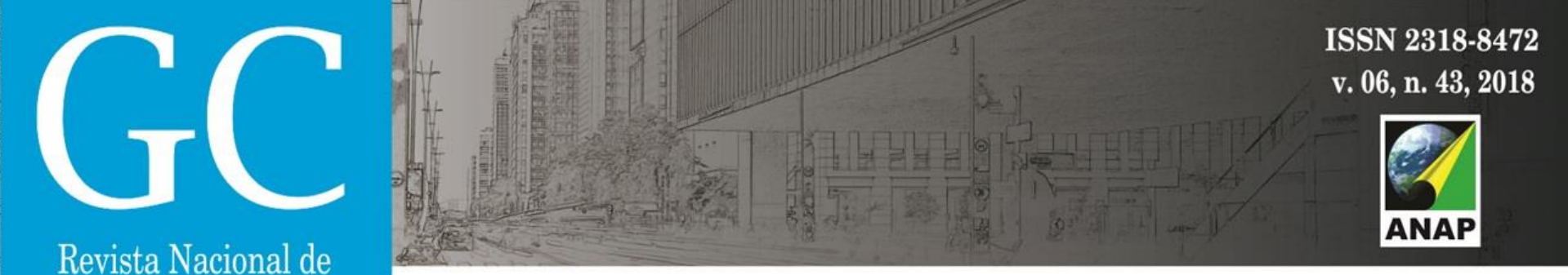

Gerenciamento de Cidades

Caconde, Casa Branca e outras localidades. Francisco Alves Pereira, natural de Sorocaba, deu o nome a região de Bairro dos Lençóes.

\begin{abstract}
Por volta de 1825, Francisco Alves Pereira e esposa fizeram parte de uma expedição que se dirigia a Goiás, pelo Rio Tiete...abandonaram a expedição e se aventuraram a explorar o Rio Lençóis.... Francisco Alves Pereira chegando a nossa região, batizou-a com o nome de Bairro dos Lençóes. Como desbravador, ficou residindo por pouco tempo no Ribeirão do Paraizo (CHITTO, 2008, p. 17)
\end{abstract}

Também foi importante a participação de mineiros no povoamento da região. Nos anos de 1850, a procura de terras, o mineiro José Teodoro de Souza ocupa a região de Botucatu e posteriormente a expedição chega em Lençóis Paulista. Fundando povoados, abrindo caminhos e trazendo povoadores de províncias de Minas (MONBEIG, 1984, p. 134). Neste momento, o Bairro de Lençóis já apresentava um núcleo compacto de habitações e constituía um posto avançado que servia de pouso aos aventureiros que iam e voltavam do sertão.

A formação do patrimônio se deu quando um grupo de oito fazendeiros compraram uma extensa área de terra de Joaquim de Oliveira Lima e doaram parte destas, no dia 22 de julho de 1858, para a constituição do patrimônio de Nossa Senhora da Piedade, padroeira da matriz da paróquia de Lençóes. O grupo era composto por: Eliseu Antunes Cardia, Fidelis Correa de Moraes, Antonio Martins Siqueira, Antonio Rodrigues de Souza, Inácio Anselmo de Souza, Antonio Teodoro de Souza (filho de José Teodoro de Souza), Felipe José Moreira e Lourenço Antonio de Siqueira (FERNANDES, 2011, p. 32).

A área doada, entre os rios Lençóes e da Prata, seria vendida à razão de mil-réis por braça para os interessados em construir residência, e a renda obtida da venda de lotes seria aplicados nas obras da igreja, posteriormente construída em madeira (FERNANDES, 2011, p. 34).

Neste novo núcleo urbano surgem a Rua da Matriz, A rua da Cadeia, a rua da Ponte Velha, a rua de Baixo. Além da rua do Comercio, onde se concentravam as atividades econômicas e maior movimento da localidade. Nela encontravam-se algumas lojas, uma botica e um armazém. Como freguesia, Lençóes ainda não possuía autonomia administrativa (estava ligada a Botucatu), o que só viria acontecer com a elevação da vila.

A partir de 25 de abril de 1865, Lençóes passava a categoria de Vila. A lei provincial n. $36^{1}$ expressa: Artigo Único: Fica elevada a cathegoria de Villa a Freguesia dos Lençóes, do município de Botucatu, subistituindo a mesma denominação e divisas autuais. (CHITTO, 2008, p. 41)

Segundo Chitto (2008), no cotidiano lencoense do final do século XIX não existiam: eletricidade, ruas pavimentadas, água encanada, rede de esgoto, e hospitais como nos centros mais desenvolvidos.

\footnotetext{
${ }^{1}$ Ver em: https://biblioteca.ibge.gov.br/visualizacao/dtbs/saopaulo/lencoispaulista.pdf Acesso: 10/10/2018
} 


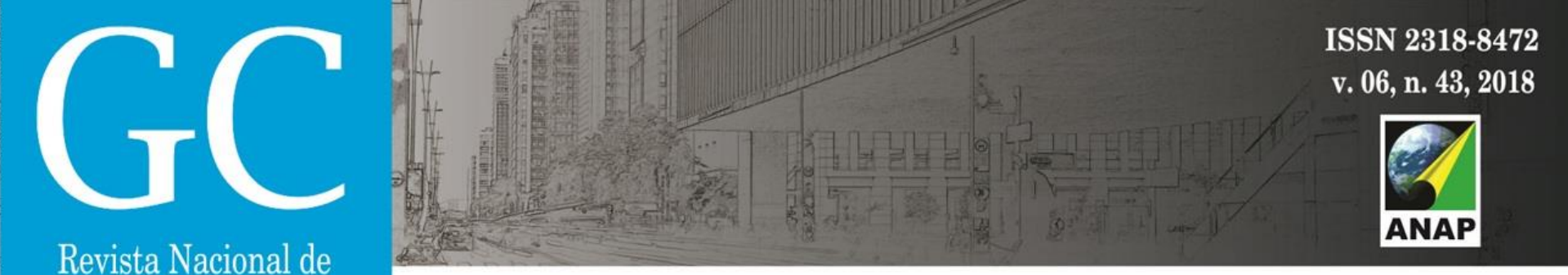

Gerenciamento de Cidades

Esta vila voltada para a economia agrícola modifica-se e se desenvolve com a aproximação dos trilhos da Sorocabana. Mudanças estruturais começam a acontecer neste território.

\section{A CHEGADA DOS TRILHOS: IMPLANTAÇÃO E O DESENVOLVIMENTO URBANO}

Os trilhos foram importantes no processo de ocupação e expansão, norteando o traçado das cidades que se formavam. A ferrovia possibilitou vida econômica estável ao futuro povoado, como também, garantiu acessibilidade e escoamento da produção, principalmente o produto café ${ }^{2}$, e influenciou nas alterações do desenho urbano do município.

A Companhia Estrada de Ferro Sorocabana foi fundada em 1870 e nasceu de uma cisão entre os acionistas da Companhia Ituana de Estradas de Ferro, fazendeiros da região de Itu e empreendedores de Sorocaba, que acabaram discordando do traçado escolhido para a implantação do trecho principal da companhia.

Na medida em que possuíam o mesmo território de interesse, de 1989 a 1907, houve uma associação entre elas formando a Companhia União Sorocabana e Ituana, atuando no território de Botucatu e chegando a Lençóis. Devido a uma crise financeira, a companhia foi encampada pelo governo Federal, e repassada ao governo do Estado de São Paulo, que arrendou a um consórcio internacional - Brasil Railway. No período de 1907 a 1919, a Sorocabana passou a ser conhecida por Sorocabana Railway. A partir de 1918, o Governo do Estado de São Paulo reassumiu a ferrovia e instituiu um programa de modernização. A Sorocabana passa a ser conhecida por Estrada de Ferro Sorocabana no período de 1919 a 1971, quando a FEPASA assumiu o controle (ABPF, 1977) $)^{3}$.

A figura 1 indica o ramal da ferrovia Sorocabana, com ligação entre Botucatu e Bauru, passando pela cidade de Lençóis Paulista.

\footnotetext{
${ }^{2}$ O binômio café-ferrovia que foi estudado de modo sistemático por Odilon Nogueira Matos (MATOS, 1970), no livro: Café e ferrovias: a evolução ferroviária de S. Paulo e o desenvolvimento da cultura cafeeira

${ }^{3}$ Ver em: http://www.abpfsp.com.br/ferrovias.htm Acesso: $12 / 10 / 2018$
} 


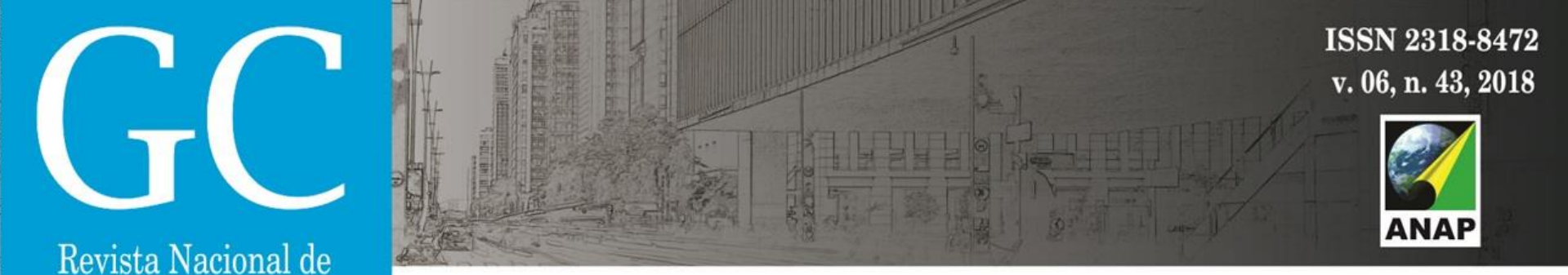

Gerenciamento de Cidades

A ferrovia foi importante para o desenvolvimento econômico, social e urbano de Lençóis. Pode-se considerar o momento de ruptura com o ambiente rural da então Vila para a construção de uma cidade modernizada e embelezada pelos trilhos do avanço que chegava, o ideal almejado pelas elites locais.

As ferrovias repercutiram na configuração da malha viária de várias cidades, no sistema de transportes urbanos e, em alguns casos, no modo de identificação das ruas, atraindo ainda para a proximidade das estações toda uma série de serviços e de comércios. As edificações das ferrovias tornaram-se marcos de grande relevância. (KHUL, 2012, p.161)

A vinda dos primeiros trabalhadores e todo arcabouço de novas tecnologias fizeram um marco no crescimento de Lençóis. Os primeiros ramos industriais foram as olarias para fabricação de tijolos e telhas, e de minerais metálicos para fornecimento a Sorocabana. Os serviços de infraestrutura, também ganharam visibilidade. Surgem grandes construções, projetos de iluminação, água e esgoto, calçamento, construções de praças públicas e arborização urbana, entre outros melhoramentos.

A iluminação elétrica pública foi inaugurada em 1909, com contrato firmado com a Empresa Luz e Força de São Manuel. Para a execução do fornecimento de energia, construiu-se uma usina no rio Lençóis, na Fazenda Jurema.

Outro melhoramento que impulsionou a urbe foi a rede telefônica municipal para atender a cidade que se desenvolvia e entrava na fase da modernização e embelezamento. Os serviços chegaram em 1908, com a instalação da rede executada por Gabriel Bombonato, e posteriormente os contratos passaram a serem lavrados com a Companhia Telefônica Brasileira (CHITTO, 2008, p. 337).

Neste sentido, percebemos que a ferrovia requalificou as infraestruturas territoriais e as urbanas. Campos (p. 25) entende que: (...) cidades do interior realizam melhoramentos em seus sistemas viários, encomendam projetos de novas redes de abastecimento e esgotamento sanitário.

\section{FERROVIA E INFRAESTRUTURA: A HISTÓRIA DO ABASTECIMENTO DE ÁGUA}

As ações que a municipalidade definiu, no sentido de dotar a cidades de melhorias, podiam ser vistas, principalmente, após a chegada das ferrovias. Para Matos (1990, p. 197) a chegada dos trilhos é quase sempre um marco na história da cidade, com a estrada de ferro vem todo um aparelhamento que ela exigia. Ghirardello (2010, p. 161) completa que a ferrovia e o seu corpo técnico foram fundamentais para viabilizar a instalação das infraestruturas urbanas de que a cidade precisava, por meio de seus especialistas.

A estação correspondia ao ponto principal para o abastecimento das locomotivas em trânsito, fato que contribuiu para que as composições se mantivessem estacionadas na estação por um razoável período de tempo (CHITTO, 2008, p. 63). 


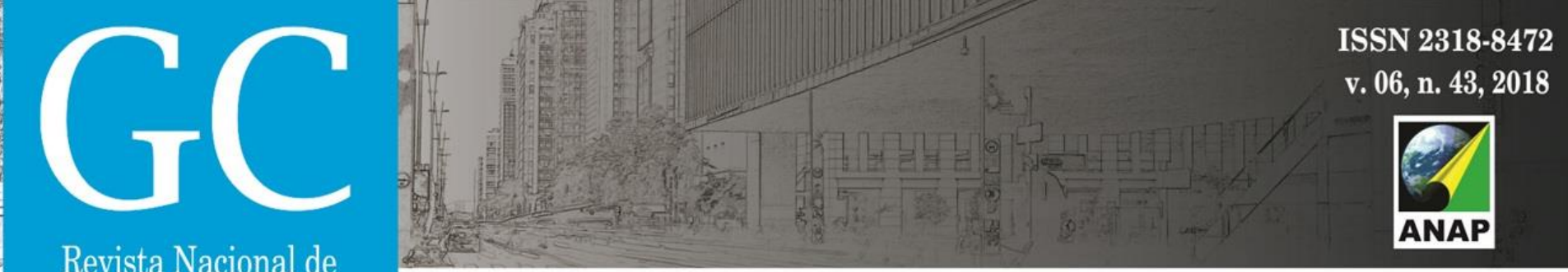

Gerenciamento de Cidades

Nos primórdios da então Vila de Lençóis, não havia serviços de abastecimento de água e a população era servida pelos poços abertos nos quintais das residências. Além disto, o excedente de água proveniente da ferrovia era usado para o abastecimento público. No entanto, os conflitos cresciam e já não era mais possível imaginar uma cidade cuja população não tivesse acesso a água potável e limpa. Importante frisar que não se encontra mais a caixa de água do complexo ferroviário próximo à estação.

Na administração do intendente Coronel Virgílio Rocha (1906 a 1907 e 1907 a 1911) reconhecia-se a necessidade de cuidar da saúde pública, e equacionar os problemas enfrentados pela questão das águas. Os projetos para equipar a cidade com abastecimento de água e esgotamento sanitário haviam sido estudados desde 1901 pelo engenheiro San Juan, na gestão do intendente Major Octaviano Martins Brisola (CHITTO, 2008, p. 283).

No entanto, as benfeitorias chegaram à população apenas em 1906, com a construção de um chafariz em uma área descampada com bica d'água, nomeada como Biquinha. Neste local, também foi construída uma praça voltada para embelezamento urbano. Tais melhoramentos foram de extrema importância para solucionar as questões relativas às epidemias, saúde e higiene urbana na cidade que se modernizava.

Em 1915, novamente o Coronel Virgílio Rocha tornou-se prefeito. No tocante as questões de saneamento, foi iniciado a instalação da adutora (projetada com uma linha de 4 mil metros de extensão) e reservatório de água denominado Marimbondo. As obras sofreram paralizações devido a morte do coronel e só foram retomadas em 1926 na gestão do Dr. Elias de Oliveira Rocha, que firmaram contrato com Virgilio Emel.

O projeto consistia na retomada da linha adutora de 4 mil metros de extensão, em tubulação de aço de cinco polegadas de diâmetro, com junção de chumbo (fabricação Manesmann) (figura 3). Entre 1927 a 1929, o projeto sofreu alteração, aumentando a linha de extensão e o material utilizado para manilhas comuns. Importante frisar que este material não era aconselhável pelo corpo técnico. 


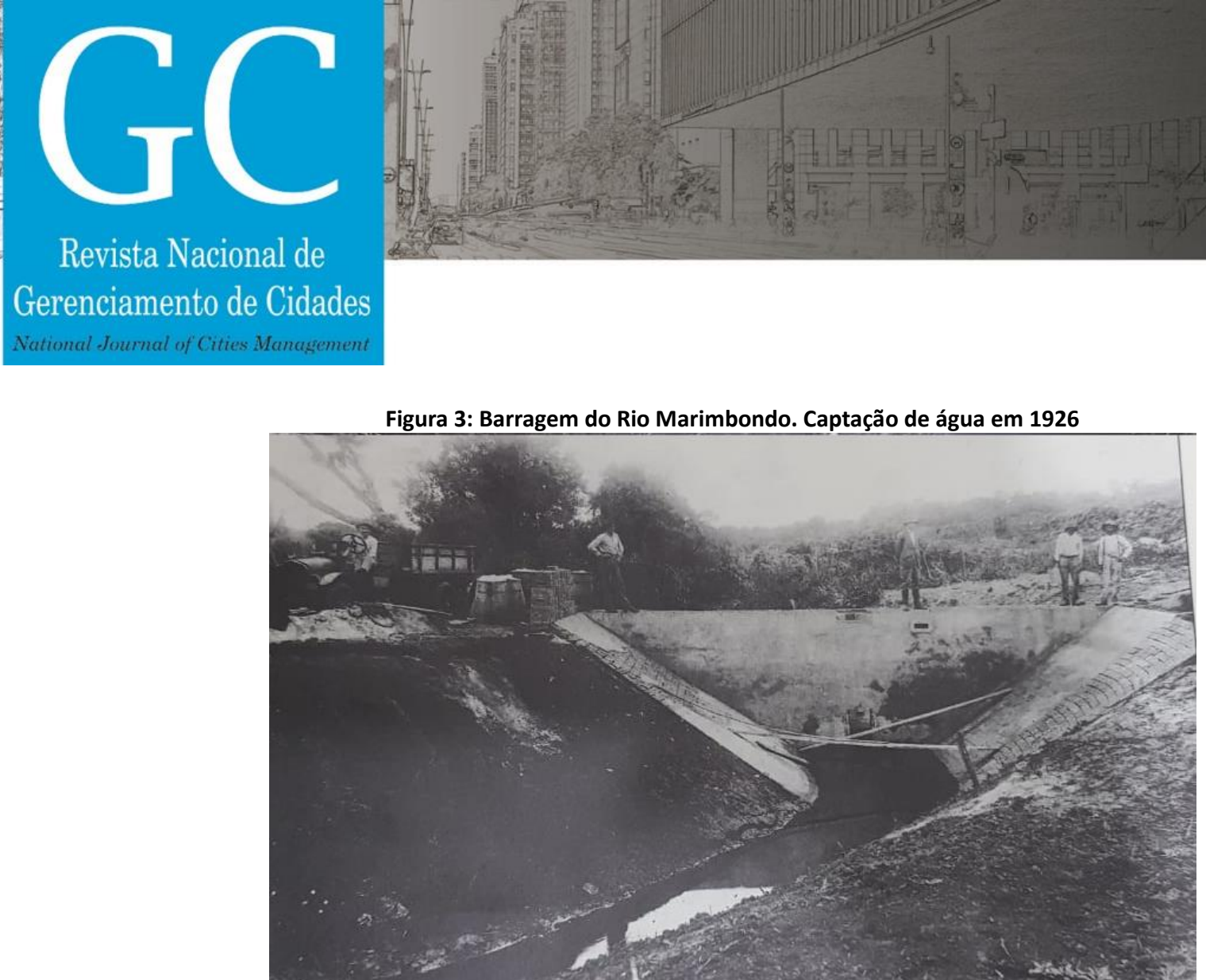

Fonte: CHITTO, 2008.

Na década de 1940, o sistema de abastecimento de água foi ampliado, com a construção de dois poços artesianos, um na margem direta e outro na margem esquerda do rio Lençóis. Estes poços estão localizados próximo a atual Estação de Tratamento de Água.

\section{CONCLUSÃO}

É notória a relação dos trilhos com a ocupação do território e o crescimento urbano. A infraestrutura de abastecimento de água é vista como medida higienizadora e de embelezamento do ambiente construído, com finalidade de desenvolvimento da cidade.

Em Lençóis, as ferrovias foram as grandes propulsoras do crescimento populacional, como também a infraestrutura ferroviária sistematizou os primeiros serviços de abastecimento de água.

Os interesses públicos locais passaram a ocupar espaço oficial na rotina da cidade e têm vez as preocupações locais com a saúde pública e o fornecimento de água para os seus moradores. Isto fica patente com a construção dos primeiros sistemas de abastecimentos de água: a construção da biquinha e as adutoras de água.

Não apenas um registro histórico da ocupação do território e ações de abastecimento de água de Lençóis, esperamos que este trabalho sirva como uma leitura e reflexão do passado. É necessário olharmos para este legado de infraestrutura como um recurso cultural, educacional e como fonte de entendermos os problemas que acontecem nas cidades atuais. E, esperamos que estas informações colaborem com estudos sobre a história urbana e o saneamento. 


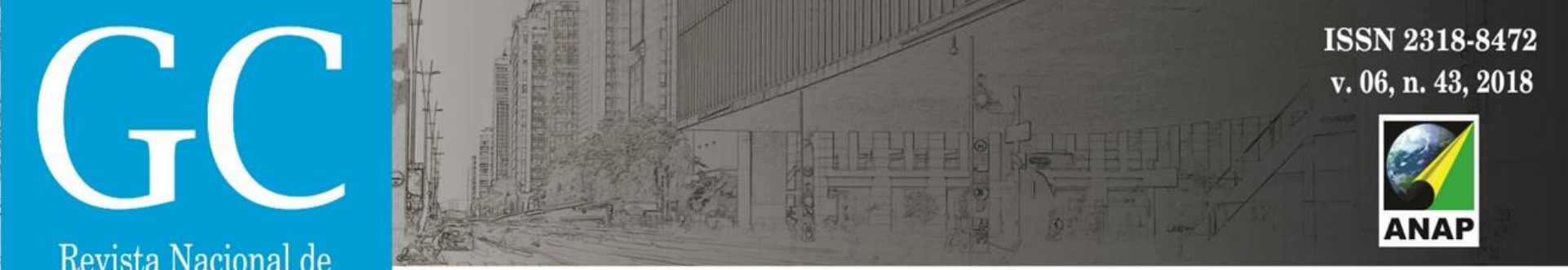

\section{AGRADECIMENTOS}

Os autores agradecem à dedicação e eficiência dos funcionários de cada museu, biblioteca, repartição pública, departamento e núcleo visitados. E a todos que direta ou indiretamente fizeram parte da produção deste trabalho.

\section{REFERÊNCIAS BIBLIOGRÁFICAS}

ABPF. Associação Brasileira de Preservação Ferroviária. Regional São Paulo. 1977

CAMPOS, Cristina. A questão da água para o abastecimento na cidade de São Paulo: as contribuições da família Paula Souza. Risco: Revista de Pesquisa em Arquitetura e Urbanismo (Online), v. 14, n. 2, p. 23-30, 23 dez. 2016.

CHITTO, Alexandre. Históri de Nossa gente: Lençóis Paulista, 150 anos. São Paulo. 2008, 461 p.

FERNANDES, Edson. Uma vila no Sertão: Lençóis século XIX. Bauru: Idea Editora. 2011, 172 p.

GHIRARDELLO, Nilson. A Formação dos patrimônios religiosos no processo de expansão urbana paulista (18501900). São Paulo: UNESP, 2010. 268 p.

GIESBRECHT, R.M. Estações Ferroviárias do Brasil: Lençóis Paulista. 2018. Disponível em: http://www.estacoesferroviarias.com.br/l/lencois.htm. Acesso em 05 out. 2018.

KÜHL, Beatriz Mugayar. A expansão ferroviária em São Paulo (Brasil) e problemas para a preservação de seu patrimônio. Tst: Transportes, Servicios y telecomunicaciones, n. 23, p. 156-187, 2012.

MATOS, Odilon .Nogueira. de. Café e ferrovias: a evolução ferroviária de S. Paulo e o desenvolvimento da cultura cafeeira. 4 ed. São Paulo: Pontes, 1990. 188 p. 